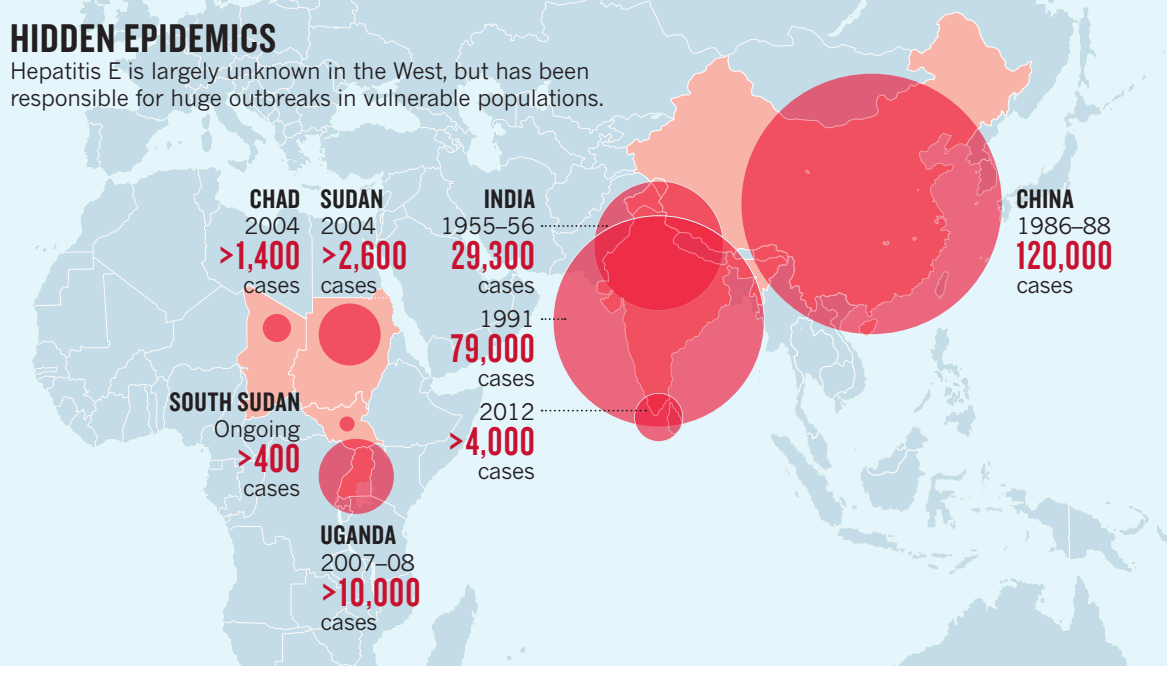

- GlaxoSmithKline had already developed a separate hepatitis E vaccine in collaboration with the US Army, which showed promise in phase II trials ${ }^{3}$. But with hepatitis E mostly occurring in developing countries, there was little commercial potential for the vaccine. "This is true not just of hepatitis E, but also many other plagues in the world," says Zhang.

Medical products for conditions such as hepatitis E that predominantly affect the developing world "are not seen as big money opportunities", agrees Jeremy Farrar, director of the Oxford University Clinical Research Unit in Ho Chi Minh City, Vietnam. "New companies operating with different funding models offer a great opportunity, and one which could have a profound impact."

Hecolin may have arrived just in time to tackle a rise in hepatitis E in Africa, where a 2007 outbreak ${ }^{4}$ in Uganda infected more than 10,000 people and killed 160. By the end of September this year, more than 200 cases of jaundice caused by hepatitis $\mathrm{E}$ had been reported in refugee camps in Kenya since August, and three refugee camps in South Sudan have seen 16 deaths and 400 cases of hepatitis E infection since July. "Cases are rising day by day, thus placing immense pressure on the available health services and resources. This is of grave humanitarian concern," said South Sudan's health ministry in a statement in September.

Xiamen University and Innovax are in talks with the World Health Organization (WHO) to register Hecolin with the organization's Prequalification Programme, which makes medicines available to agencies such as the United Nations Children's Fund and the Joint UN Programme on HIV/AIDS. "We have to be sure that these vaccines can be used anywhere," says Farrar. "It would be a great shame if these products were not available outside China."

"We have to accept that companies such as this one in China are going to be very important in the future," he adds. "The rest of us have to catch up. We need to find a way, through the $\mathrm{WHO}$, of ensuring the absolute transparency, safety and effectiveness of their vaccines." -

1. Zhuang, H., Cao, X. Y., Liu, C. B. \& Wang, G. M. Gastroenterol. Jpn. 26, 135-138 (1991).

2. Zhu, F.-C. et al. Lancet 376, 895-902 (2010).

3. Shrestha, M. P. et al. N. Engl. J. Med. 356, 895-903 (2007).

4. Teshale, E. H. et al. Emerg. Infect. Dis. 16, 126-129 (2010).

\title{
Bid to curb fried-food chemical goes cold
}

\section{Acrylamide levels still too high in Europe's food, says report.}

\section{BY KATHARINE SANDERSON}

$\mathrm{T}$ The rich, roasted aroma of coffee or the golden-brown colour of crispy French fries are enough to set most mouths watering. But the high-temperature cooking that gives these foods their alluring taste, scent and texture also adds a sting: acrylamide, a probable human carcinogen.

Swedish scientists discovered in 2002 that a wide range of baked and fried goods contain worryingly high levels of acrylamide ${ }^{1}-$ a simple organic molecule that is a neurotoxin and carcinogen in rats. The finding sparked an international effort to reduce concentrations of the chemical by changing ingredients and cooking methods.

Ten years on, a report ${ }^{2}$ from the European Food Safety Authority (EFSA) in Parma, Italy, suggests that this effort has stalled, amid patchy monitoring, uncertainty about acrylamide's true health effects and the challenge of weeding out a molecule present in hundreds of products.

Soon after the Swedish discovery, two teams - one led by chemist Donald Mottram at the University of Reading, UK, the other by Richard Stadler at Nestlé in Lausanne, Switzerland - unpicked the chemistry behind the problem ${ }^{3,4}$. They found that sugars and amino acids such as asparagine found in potatoes and cereals were making acrylamide $\left(\mathrm{C}_{3} \mathrm{H}_{5} \mathrm{NO}\right)$ as a by-product of the Maillard reaction, the very process that generates the heady blend of colour, flavour and taste in cooked foods.

Subsequent epidemiological studies involving tens of thousands of people have looked for links between acrylamide and various forms of cancer in humans, including breast ${ }^{5}$ and colorectal cancer ${ }^{6}$. For the most part, the results have been negative. In 2007, however, a Dutch study $^{7}$ of almost 2,600 women found that, among those who had never smoked, women consuming about 40 micrograms of acrylamide per day doubled their risk of developing cancers of the womb or ovaries, compared with those taking in roughly $10 \mu \mathrm{g}$ per day. And last month, a study ${ }^{8}$ showed that women who ate acrylamide-rich food during pregnancy tended to give birth to smaller babies.

Despite the uncertainties over the dangers of acrylamide, Europe's legislators and food producers vowed to take action. Since 2005, the industry group FoodDrinkEurope has maintained a 'toolbox' of tactics to help reduce acrylamide levels, such as changing potato varieties or storage conditions, and reducing cooking temperatures. According to Beate Kettlitz, the group's director of food policy, $90 \%$ of large and medium-sized companies in Europe now select potato varieties with low levels of the sugars that can form acrylamide, and all control French-fry cooking times to limit browning.

In 2007, the European Commission instructed the EFSA to collate yearly data on acrylamide levels. Last week, the authority released the most recent figures ${ }^{2}$ showing that acrylamide levels in finished food products hardly changed between 2007 and 2010. There have been isolated successes: in soft bread, for example, mean acrylamide levels dropped from 75 to $30 \mu \mathrm{g}$ per kilogram. But for crispbreads, 
the mean actually rose, from 232 to $249 \mu \mathrm{g} \mathrm{kg}{ }^{-1}$. Overall, 6-17\% of the food categories tested exceeded 'indicative values of concern" ${ }^{\text {' }}$ set out by the European Commission in 2011 (see 'Would you like acrylamide with that?').

Mottram, who has worked closely with the food industry to reduce acrylamide levels, says that he is disappointed the report does not reflect the huge strides taken by industry, not least in the period 2002-06.

The EFSA acknowledges that assessing whether the industry's efforts are bearing fruit will take many years of more consistent sampling. For the current report, the agency relied on European Union (EU) member states to collect and submit acrylamide data. The response was inconsistent: only 16 of 25 countries provided data for every year of the survey, and submissions also waned over time. Despite submitting data every year, Belgium provided no figures at all on its beloved frites, for example.

Since 2010, the EU has required member countries to collect acrylamide data, and the EFSA report suggests that monitoring is improving as a result. Europe certainly takes acrylamide more seriously than other parts of the world. The US Food and Drug Administration has not routinely collected data on acrylamide in food since 2006, although it is currently calling on the food industry to submit more data, says agency spokesman Sebastian Cianci.
WOULD YOU LIKE ACRYLAMIDE WITH THAT?

Figures for 2007-10 suggest that fried and baked foods in Europe often contain worryingly high levels of the probable carcinogen acrylamide.

\begin{tabular}{|l|l|l|}
\hline Food & $\begin{array}{l}\text { Indicative value } \\
\text { of concern } \\
\left(\mu \mathrm{kg}^{-1}\right)\end{array}$ & $\begin{array}{l}\text { \% Samples } \\
\text { exceeding } \\
\text { indicative value }\end{array}$ \\
\hline French fries & 600 & 12 \\
\hline Potato crisps & 1,000 & 17 \\
\hline $\begin{array}{l}\text { Instant coffee } \\
\text { Soft bread }\end{array}$ & 900 & 10 \\
\hline $\begin{array}{l}\text { Crispbreads, } \\
\text { biscuits }\end{array}$ & 500 & 7 \\
\hline
\end{tabular}

Source: ref. 2

Mottram is also developing new ways to tackle the problem. In August, he showed that acrylamide levels in French fries can be predicted from the cooking methods and the presence of key precursor chemicals in the partially cooked, frozen fries used by fast-food restaurants $^{10}$. This model revealed that a change to the potato blanching process could make a big difference to the final acrylamide level. "The industry is not giving up on this," he says.

Plant breeding and genetic modification could also help, by creating varieties with lower levels of acrylamide precursors. Nevertheless, the chemical will always be present in our food, says Margareta Törnqvist from Stockholm University, who led the team that originally discovered the problem. "Acrylamide is natural; you can't reduce it to zero," she says.

1. Tareke, E., Rydberg, P., Karlsson, P., Eriksson, S. \& Törnqvist, M. J. Agric. Food Chem. 50, 4998-5006 (2002).

2. European Food Safety Authority EFSA J. 10, 2938 (2012).

3. Mottram, D. S., Wedzicha, B. L. \& Dodson, A. T. Nature 419, 448-449 (2002).

4. Stadler, R. H. et al. Nature 419, 449-450 (2002).

5. Wilson, K. M. et al. Am. J. Epidemiol. 169, 954-961 (2009).

6. Larsson, S. C., Åkesson, A., Bergkvist, L. \& Wolk, A. Eur. J. Cancer 45, 513-516 (2009).

7. Hogervorst, J. G., Schouten, L. J., Konings, E. J., Goldbohm, R. A. \& van den Brandt, P. A. Cancer Epidemiol. Biomarkers Prev. 16, 2304-2313 (2007).

8. Pedersen, M. et al. Environ. Health Perspect. http:// dx.doi.org/10.1289/ehp.1205327 (2012).

9. Commission Recommendation of 10.1.2011 on Investigations into the Levels of Acrylamide in Food (European Commission, 2011); available at go.nature.com/tkdm89.

10. Parker, J. K. et al. J. Agric. Food Chem. 60, 9321-9331 (2012).

\section{CORRECTION}

The story 'Texas cancer fund seeks fresh start' (Nature 490, 459-460; 2012) gave the wrong location for Arizona State University with respect to Raymond DuBois' new post. The campus is in Tempe, not Tucson. 